Research Paper

International Journal of Biological Sciences

ISSN 1449-2288 www.biolsci.org 2008 4(5):300-308

(C) Ivyspring International Publisher. All rights reserved

\title{
Eifect of exercise training on calpain systems in lean and obese Zucker rats
}

\author{
Yao-Yuan Hsieh ${ }^{1,2^{*}}$, Chi-Chen Chang ${ }^{1,2^{*}}$, Kung-Hao Hsu ${ }^{3}$, Fuu-Jen Tsai ${ }^{2,4}$, Chih-Ping Chen ${ }^{5}$, Horng-Der \\ Tsai 6 凶
}

1. Department of Obstetrics and Gynecology, China Medical University Hospital, Taichung, Taiwan.

2. School of Chinese Medicine, College of Chinese Medicine, China Medical University.

3. Department of Animal Science and Biotechnology, Tunghai University, Taichung, Taiwan.

4. Department of Pediatrics and Genetics, China medical University, Taichung, Taiwan.

5. Department of Obstetrics and Gynecology, Mackay Memorial Hospital, Taipei, Taiwan.

6. Department of Obstetrics and Gynecology, Changhua Christian Hospital, Changhua, Taiwan

* Chi-Chen Chang, Yao-Yuan Hsieh and Kung-Hao Hsu contributed equally to this work.

$\triangle$ Correspondence to: Horng-Der Tsai, M.D., Department of Obstetrics and Gynecology, Changhua Christian Hospital, Changhua, Taiwan. Telephone: 886-4-22371134; Fax: 886-4-22292942; E-mail: hongte2000@yahoo.com.tw.

Received: 2008.05.15; Accepted: 2008.09.05; Published: 2008.09.09

Exercise training plays a major role in the improving physiology of diabetes. Herein we aimed to investigate the influence of exercise upon the calcium-dependent calpain-isoform expressions of lean or obese Zucker rats, a model of obesity and type II diabetes (NIDDM). Five-month-old rats were divided: (1) obese sedentary (OS, n=7); (2) obese exercise (OE, n=7); (3) lean sedentary (LS, n=7); (4) lean exercise (LE, n=7). After 2-month exercise (treadmill running), the body weight (BW) and expression of calpain 10, $\mu$-calpain, and m-calpain in skeletal muscles were determined by RT-PCR, using $\beta$-actin as internal standard. We found exercise is useful for BW lossing, especially in the obese rats. The BW difference between OS and OE rats (69 g vs. $18.2 \mathrm{~g}$ ) was more significantly than that between LS and LE rats (41.8 g vs. $28.7 \mathrm{~g}$ ). The calpain 10 expression of LS rats (0.965) was lower than that of LE rats (1.006), whereas those of OS and OE were comparable. The $\mu$ - or m-calpain expressions of sedentary groups (OS, LS) was significantly higher than those of exercise groups (OE, LE). The $\mu$-calpain expression (1.13/0.92) and m-calpain expression (1.01/0.99) of OS/LS rats was significantly higher than those of OE/LE rats [1.07/0.9 ( $\mu$-calpain); 0.97/0.95 (m-calpain)]. We concluded that the $\mu$ - or m-calpains in skeletal muscle are regulated by exercise in both lean and obese Zucker rats. Exercise and BW controlling might improve the physiopathology of obesity and diabetes. Both $\mu$ - or m-calpains might become useful markers for prognoses of diabetes.

Key words: Calpain, diabetes, exercise, obesity, skeletal muscle

\section{Introduction}

Diabetes is a multifactorial and heterogeneous disorder with both genetic and environmental factors contributing to its development. Type 2 or non-insulin-dependent diabetes mellitus (NIDDM) is the most common form of diabetes, affecting approximately $4 \%$ of world's adult population. NIDDM is resulted from the contribution of many genes interacting with different environmental factors, which produce wide variation in the clinical courses. The dramatic worldwide prevalence of NIDDM over the past decades might be resulted from the relatively recent changes in diet, life style and physical activities.

Skeletal muscle is the standard organ of insulin-mediated glucose uptake. Exercise increases the rate of glucose uptake into the contracting skeletal muscle [1]. This effect of exercise is similar to the action of insulin on glucose uptake. Exercise increases skeletal muscle glucose uptake, which involves the translocation of glucose transporters to the plasma membrane and transverse tubules. Exercise decreased he basal and glucose-induced plasma insulin levels and improved sensitivity to insulin in obese humans $[2,3]$.

Zucker diabetic fatty rat $(\mathrm{ZDF}, f a / f a)$ presents a range of metabolic aberrations such as hyperglycemia, hyperinsulinemia, hyperlipidemia, and adipocyte hypertrophy, which are similar to those of NIDDM individuals as well as useful animal model for NIDDM [4, 5]. Exercise training has been present to improve the severe insulin resistance found in ZDF rats and to reduce plasma insulin [1]. The mechanism through which exercise training improves the skeletal muscle 
insulin resistance of the ZDF rats has yet to be fully elucidated [6].

Calcium-dependent proteinase (calpain) system has been found in every vertebrate cell. The contractions of skeletal muscle are associated with calcium-dependent protease and calpain system [7, 8]. Calpain is a cytoplasmic cysteine protease activated by calcium ions [9]. Calpains are calcium-modulated proteases which respond to calcium signals by removing limited portions of protein substrates, thereby irreversibly modifying their functions. Calpain-isoforms take part of a variety of calcium-regulated cellular processes such as signal transduction, cell proliferation, cycle progression, differentiation, apoptosis, membrane fusion, and platelet activation [14-17]. Furthermore, calpain has been reported to be associated with the risk of NIDDM [10,18,19].

Since exercise increases the rate of glucose uptake of skeletal muscle as well as improving the pathophysiology of NIDDM individuals, it is logical to suspect its influences upon the presentations of calpain-isoforms. Reviewing the related literatures, the mechanism through which exercise training improves the calpain presentation remains obscure. Herein we firstly intended to evaluate the effects of exercise upon the body weight and calpain-isoform (calpain 10, $\mu$-calpain, m-calpain) expressions of obese and lean zucker rats.

\section{Materials and Methods}

\section{Animals}

The studies were performed on lean $(\mathrm{Fa} / \mathrm{Fa}$ or $\mathrm{Fa} / \mathrm{fa}$ ) and obese (fa/fa) male Zucker rats with genetic mutation during 5 months old [5]. Zucker rats were born by breeders purchased from Charles River Lab in France. Each rat was housed in a separate cage. All groups of rats were studied at the same age. Their BWs before exercise were comparable. Mean BW in each group (OS/OE/LS/LE) were 56.3, 55.9, 38.7, 37.9g, respectively. The ambient temperature was maintained between $22-24^{\circ} \mathrm{C}$ and the animals were kept on an artificial 12-h light-dark cycle. The light period began at 7:00 A.M. Rats were provided with standard laboratory chow and water [5]. All protocols were approved by the Institutional Animal Care and Use Committee (China Medical University, Taichung, Taiwan).

\section{Exercise Training}

A total of 14 lean and 14 obese rats were randomly divided into four age-matched groups: (1) lean sedentary (LS, $n=7$ ); (2) lean exercise ( $L E, n=7)$; (3) obese sedentary (OS, n=7), and (4) obese exercise (OE, $\mathrm{n}=7)$. Initially, 28 rats were screened whether they could run on a motor-driven treadmill at $20 \mathrm{~m} / \mathrm{min}$,
$0 \%$ incline, for $60 \mathrm{~min}$. Rats in the exercise groups were trained by running for 8 weeks on a motorized treadmill in the morning. For exercise experiments, obese Zucker rats received one session of exercise, which consisted of running on a treadmill at $20 \mathrm{~m} / \mathrm{min}, 0 \%$ incline, for $60 \mathrm{~min}$. The exercise intensity for both $\mathrm{OE}$ and LE rats was approximately $70 \%$ of the peak pulmonary oxygen consumption $(59.6+1.3 \mathrm{~mL} / \mathrm{kg}$ per $\mathrm{min}$ ) [5]. Training protocols were began when the rats were 5 months old and finished when rats were 7 months old. Lean and obese rats in the sedentary groups (LS, OS) were removes from their cages once a day for 7 day/week and placed on the stationary treadmill for $60 \mathrm{~min}$ to account for handling stress.

\section{$R N A$ extraction and Reverse transcription reaction}

All rats were killed with overdosage-anesthesia (isofluorane) at $48 \mathrm{~h}$ after the end of their last training session to minimize acute exercise effects from the last training bout. Rats in the sedentary groups were killed at the same time as their trained counterparts. The RNA extraction and RT-PCR procedures were performed as previous described [20]. After all rats had been killed, all tissues were removed immediately and washed with cold phosphate buffer. These tissues were cut into potions and stored separately at $-70^{\circ} \mathrm{C}$. In this survey, only skeletal muscles from bilateral legs were used for analyses. Total RNAs from the skeletal muscle were extracted by Trizon (Invitrogen). One microgram of each total RNA was reverse transcribed into cDNA using the RNA PCR kit (Invitrogen) using oligo (dT) primer. The reaction was carried out at $50^{\circ} \mathrm{C}$ for $60 \mathrm{~min}$. The reverse transcriptase was inactivated with incubation at $98^{\circ} \mathrm{C}$ for $5 \mathrm{~min}$, and kept at $4^{\circ} \mathrm{C}$.

\section{PCR conditions}

The reverse transcription reaction products were measured by PCR analysis, using mRNA encoding rat $\beta$-actin as an internal standard. All PCR reactions were performed as follows: $1 \mu \mathrm{l}$ of cDNA was used for amplification with $1 \mathrm{U}$ Taq DNA polymerase (Qiagen, Hilden, Germany), $5 \mu$ l PCR buffer, $5 \mu 110$ mM dNTPs (each), and 1 pmol of each specific upstream and downstream primer. The individual primer sequences were designed as following: $\mu$-Calpain: 5'-GGTCA GCCTGTGCACTTGAAGCG and 3'-TTGTGGGGCTCGAAGGTGGAGGG; m-calpain: 5'-CACAACCCGAGCCAGGGAGCG and 3'-TTGTGGGGCTCGAAGG TGGAGGG; Calpain 10: 5'- AACCCAGCGAGGTGTGTGTGGCTGTT and 3'-GCAGTGTTGCTGTAGGGTGATACGGATG. PCR amplification was performed using the following conditions: $94^{\circ} \mathrm{C}$ for $5 \mathrm{~min}$, then 30 cycles of $94^{\circ} \mathrm{C}$ for $1 \mathrm{~min}$, $55^{\circ} \mathrm{C}$ for $1 \mathrm{~min}$, and $72^{\circ} \mathrm{C}$ for $1 \mathrm{~min}$, with a final elongation of $72^{\circ} \mathrm{C}$ for $7 \mathrm{~min}$. The PCR products were ana- 
lyzed by electrophoresis in $2 \%$ agarose gel containing $0.5 \mu \mathrm{g} / \mathrm{ml}$ ethidium bromide.

\section{Preparation of tissue and cell extracts for Western blotting}

Obese Zucker rats skeletal muscle were homogenized in ice-cold Buffer B (20 mM Tris- $\mathrm{HCl}(\mathrm{pH} 7.5)$, $0.25 \mathrm{M}$ sucrose, $50 \mathrm{mM} \beta$-mercaptoethanol, $1 \mathrm{mM}$ PMSF, $200 \mu \mathrm{g} / \mathrm{ml}$ of leupeptin, $5 \mathrm{mM}$ EDTA, $2 \mathrm{mM}$ EGTA, $10 \mathrm{mM}$ benzamidine) using a homogenizer. Tissues were centrifuged at $100,000 \times \mathrm{g}$ for $30 \mathrm{~min}$ at $4^{\circ} \mathrm{C}$. Supernatants were used as the cytosolic fraction. To obtain membrane fractions, the pellets were washed and extracted with Buffer B containing 1\% Triton X-100. After $30 \mathrm{~min}$ incubation at $4^{\circ} \mathrm{C}$, the samples were centrifuged at $100,000 \times \mathrm{g}$ for $30 \mathrm{~min}$ yielding the solubilized membrane fraction.

Protein concentrations of individual samples were determined by the protein-dye binding reaction on an acetate membrane and a light microscope with an automatic exposure instrument [21]. In briefly, the protein was stained with Coomassie Brilliant Blue G-250 (Nacalai Tesque, Inc, Kyoto, Japap) and absorbed by discoidal cellulose acetate membranes (Jooko Sangyo, Co., Ltd, Tokyo, Japan), which was further examined by a light microscope. A liner relation was detected between the intensity of dye binding to protein and exposure time.

\section{Western blot analysis of $\mu$-calpain and $m$-calpain}

Protein samples were subjected to $10 \%$ SDS-PAGE according to the method of Laemmli [22]. In briefly, nuclear extracts were incubated in buffer at $37^{\circ} \mathrm{C}$ for $10 \mathrm{~min}$ and fractionated by electrophoresis. The separated protein were electrophoretically transferred to a $0.22 \mu \mathrm{m}$ nitrocellulose membranes (Hybond-C Super or Hybond-ECL) at $4^{\circ} \mathrm{C}$ overnight using a Bio-Rad Transfer Blot apparatus (30 mAmp). Nonspecific sites were blocked with $5 \%$ skim milk in TTBS (50mM Tris- $\mathrm{HCl}, \mathrm{pH}$ 7.5, $0.15 \mathrm{M} \mathrm{NaCl}, 0.05 \%$ Tween-20) for $1 \mathrm{~h}$ at room temperature. The membranes were incubated for $2 \mathrm{hr}$ at room temperature and were sequentially diluted with 1:2500 of anti-rabbit $\mu$ - or m-calpain. The membranes were washed and incubated for $1 \mathrm{hr}$ with 1:2000 dilution of secondary (AP-conjugated goat anti-rabbit IgG). After three time washings, antibody-reactive bands were visualized by the ECL detection system (Amersham). The blots were scanned using a Gene Gnome syngene Bio imaging system.

\section{Statistical analysis}

All data were presented as mean \pm standard deviation (SD). The SAS system (Version 8.1, SAS Institute Inc., Cary, North Carolina, USA) with unpaired student's $t$-test was utilized for statistical analyses. A $p$-value $<0.05$ was considered statistically significant.

\section{Results}

\section{Body weight}

In both lean and obese rats, the final body weight of sedentary group was significantly higher than that of exercise group. The BW difference between OS and OE rats was more significantly than that between LS and LE rats. After exercise training for 8 weeks, in obese group, the final body weight of OS rats was higher than those of OE rats $(69 \pm 19.2 \mathrm{~g}$ vs. $18.17 \pm 11.09$ $\mathrm{g}, p<0.001$, Figure 1A). In the lean group (non-diabetic rats), the body weight of LS was also higher than those of LE $(41.75 \pm 2.87 \mathrm{~g}$ vs. $28.67 \pm 6.41 \mathrm{~g}, p<0.05$, Figure 1B). The differences of body weight between exercise and sedentary groups were due to the influences of massive exercise.

\section{Calpains mRNA expression in skeletal muscle}

In obese group, there were no significant differences in calpains 10 mRNA expression of skeletal muscle between sedentary (OS ) and exercised rats (OE) $(1.105 \pm 0.0311$ vs. $1.072 \pm 0.0084, p=0.053$; Figure $2 \mathrm{~A})$. In contrast, in the lean group, the calpain 10 mRNA expression of sedentary rats (LS) was significantly lower than in exercise rats (LE) $(0.965 \pm 0.031 \mathrm{vs}$. $1.006 \pm 0.024 ; p<0.05$; Figure $2 \mathrm{~B})$. In both lean and obese rats, the $\mu$ - or $\mathrm{m}$-calpain expressions of sedentary group was higher than those of exercise group. In obese groups, the $\mu$-calpain mRNA expression of skeletal muscle in sedentary rats (OS) was higher than that in exercised rats (OE) $(1.13 \pm 0.038$ vs. $1.068 \pm 0.023$; $p<0.05$; Figure $3 \mathrm{~A})$. In the lean groups, the $\mu$-calpain expression of LS rats was higher than that of LE rats ( $0.92 \pm 0.014$ vs. $0.898 \pm 0.013, p<0.05$; Figure 3B). The $\mathrm{m}$-calpain expression of OS/LS rats was also higher than that of OE/LE rats $(1.01 \pm 0.0141 / 0.995 \pm 0.0173$ vs. $0.97 \pm 0.021 / 0.9467 \pm 0.0137, \mathrm{p}<0.05,0.001$, respectively, Figure $4 \mathrm{~A}, \mathrm{~B})$. In obese groups, the m-calpain mRNA expression of skeletal muscle in sedentary rats (OS) was higher than that in exercised rats (OE) $(1.01 \pm$ 0.014 vs. $0.97 \pm 0.021 ; P<0.05$; Figure $4 \mathrm{~A})$. In the lean groups, the $\mathrm{m}$-calpain expression of LS rats was also higher than that of LE rats $(0.995 \pm 0.017$ vs. $0.947 \pm$ $0.014, P<0.001$; Figure 4B). 
(1A) Obese Zucker rats $\left({ }^{*} p<0.001\right)$

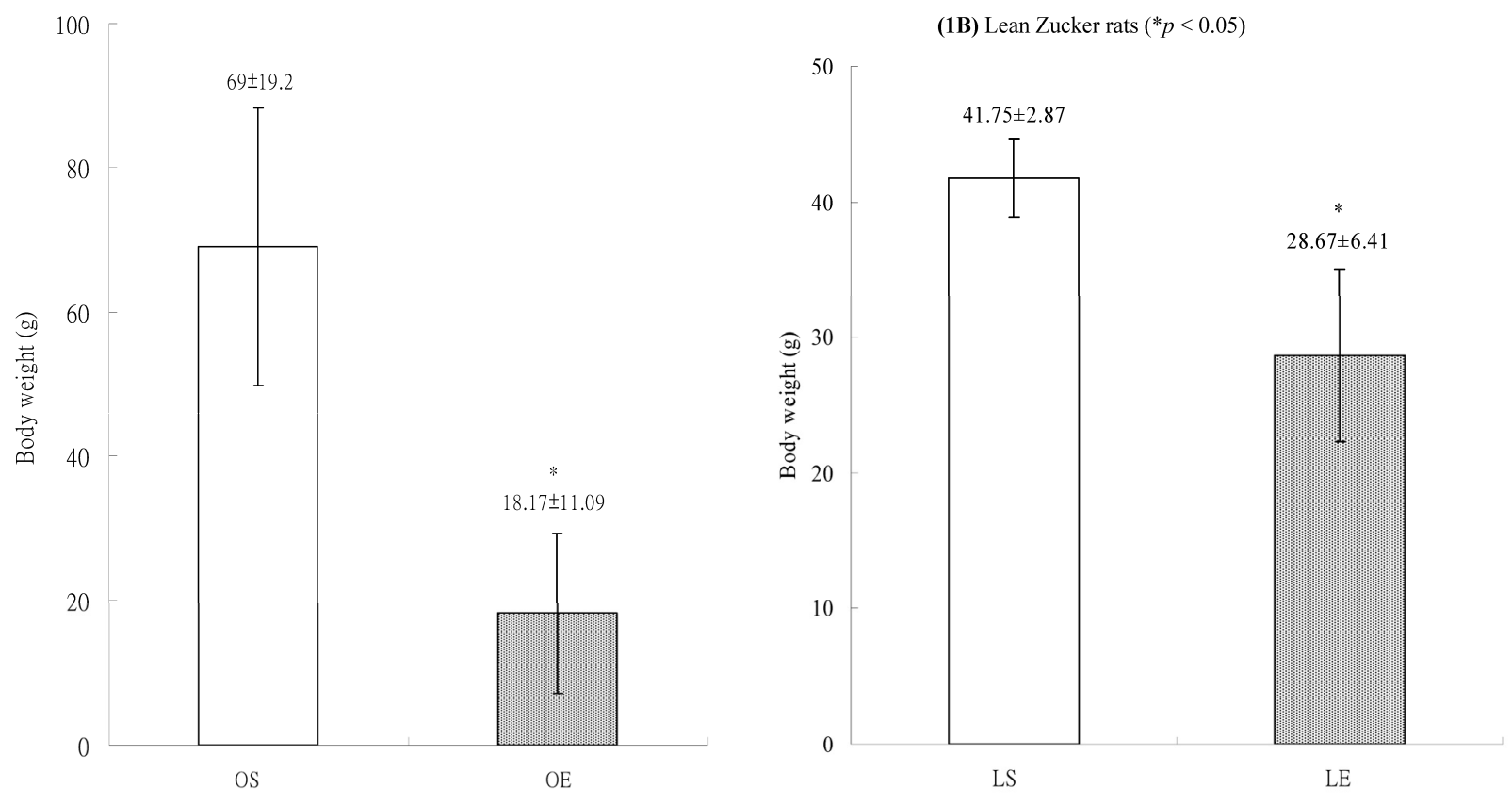

Figure 1. Body weights of (A) obese and (B) lean Zucker rats after sedentary or exercise treatment.
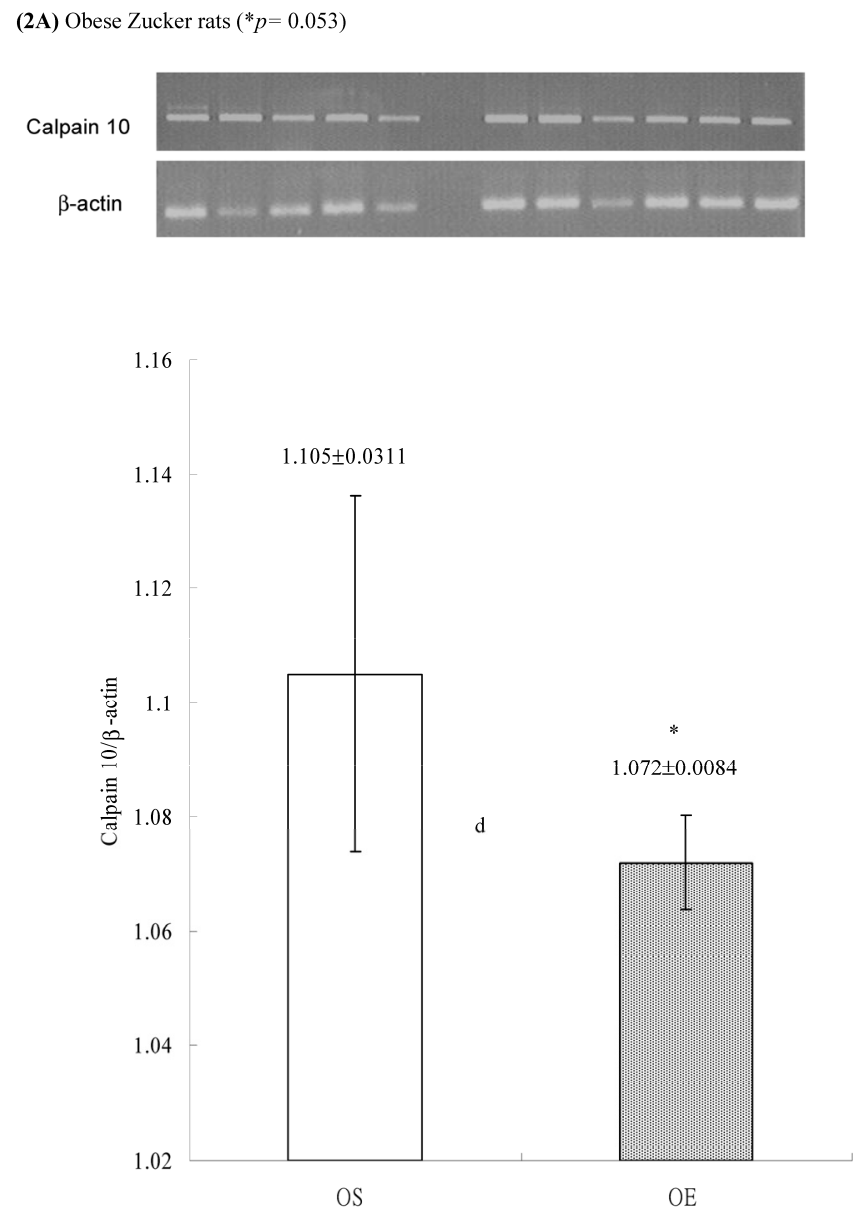

(2B) Lean Zucker rats $\left({ }^{*} p<0.05\right)$

Calpain 10

$$
\beta \text {-actin }
$$
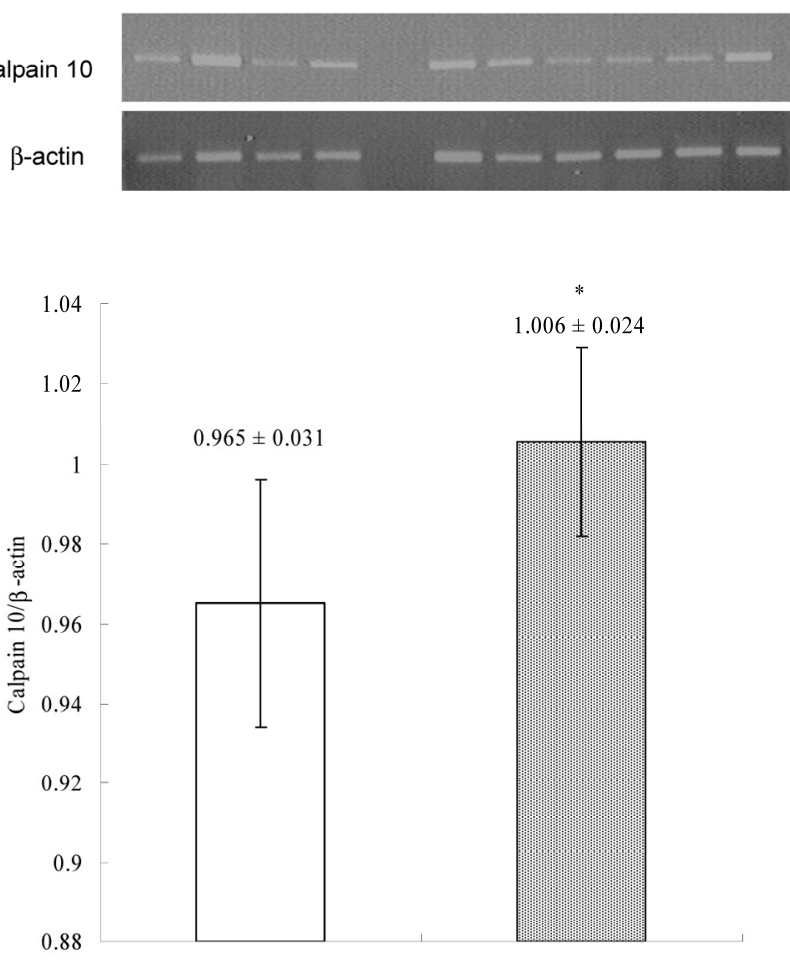

LS

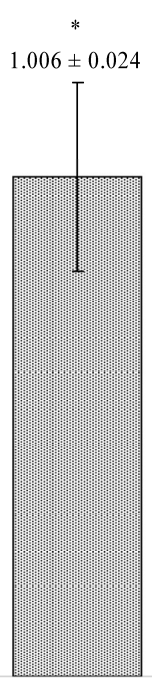

LE

Figure 2. Electrophoreses and expression ratios of calpain 10 and $\beta$-actin mRNA in skeletal muscle of (A) obese and (B) lean Zucker rats after sedentary or exercise treatment. 
(3A) Obese Zucker rats $(* p<0.05)$
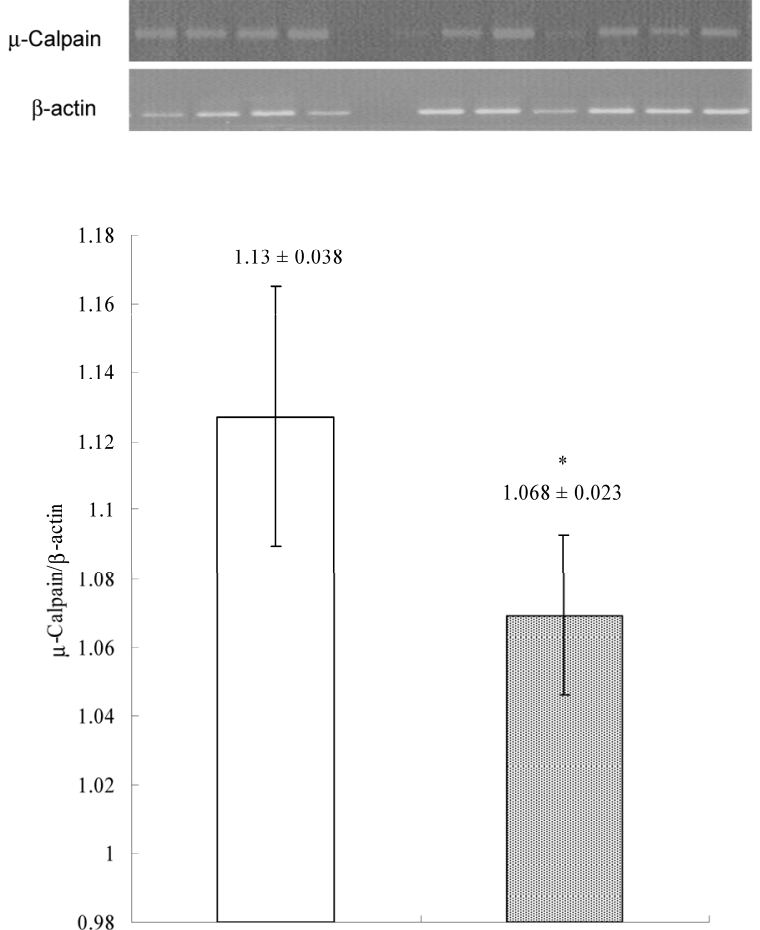

OS

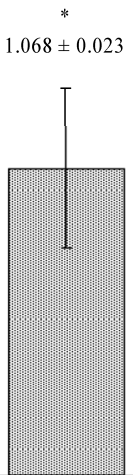

$\mathrm{OE}$
(3B) Lean Zucker rats $\left({ }^{*} p<0.05\right)$
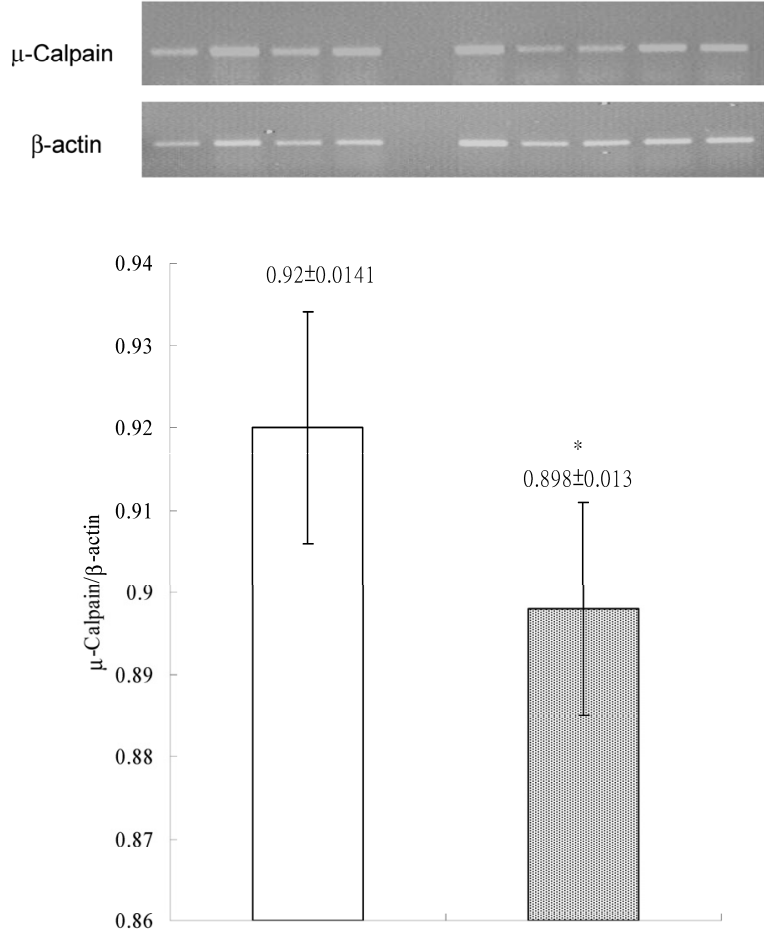

LS

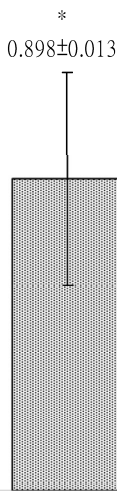

LE

Figure 3. Electrophoreses and expression ratios of $\mu$-calpain and $\beta$-actin mRNA in skeletal muscle of (A) obese and (B) lean Zucker rats after sedentary or exercise treatment.

(4B) Lean Zucker rats $\left({ }^{*} p<0.001\right)$

(4A) Obese Zucker rats $\left({ }^{*} p<0.05\right)$
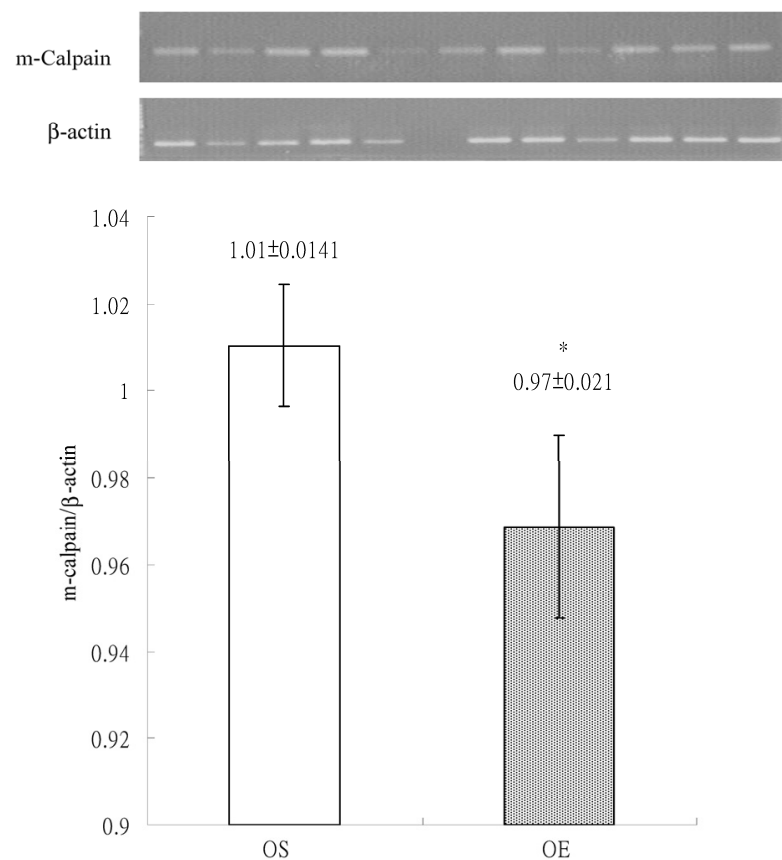

m-calpain

$\beta$-actin

$$
1.02
$$
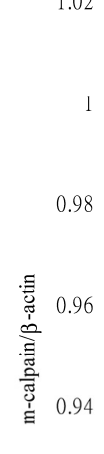

$0.97 \pm 0.02$

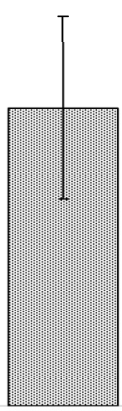

OE

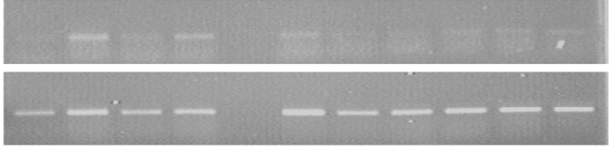

$0.995 \pm 0.0173$

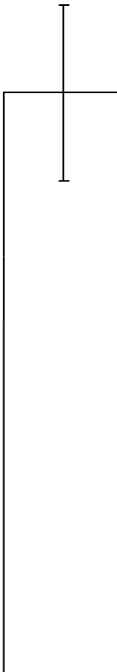

LS
$*$

$0.9467 \pm 0.0137$

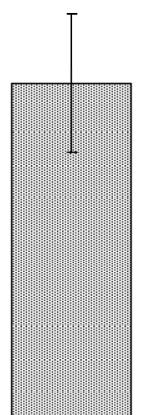

LE

Figure 4. Electrophoreses and expression ratios of m-calpain and $\beta$-actin mRNA in skeletal muscle of (A) obese and (B) lean Zucker rats after sedentary or exercise treatment. The $\beta$-actin is internal control. 


\section{Western blot analysis of calpain}

Effects of exercise on cytosolic and membrane-bound $\mathrm{m}$ - and $\mu$-calpain in skeletal muscle of obese Zucker rats were determined by Western blot analysis. The protein levels of membrane-bound $\mathrm{m}$ and $\mu$-calpain between obese-sedentary (OS) and obese-exercise (OE) rats were presented on Figure 5A and $5 \mathrm{~B}$. The $\alpha$-tubulin was determined as internal control.

(5A) $\mu$-calpain

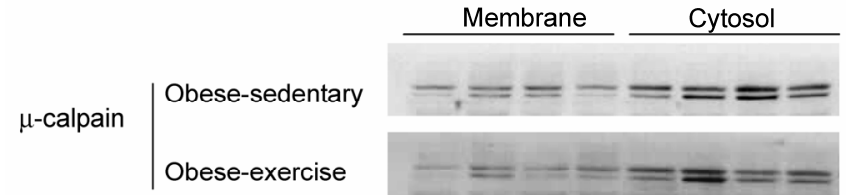

$\alpha$-tubulin

(5B) m-calpain

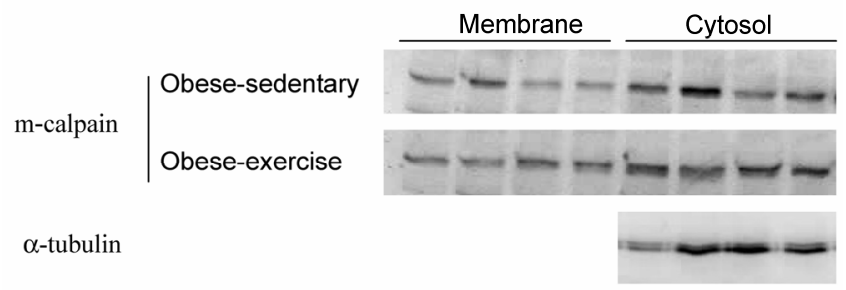

Figure 5. Effects of exercise on cytosolic and membrane-bound (A) $\mu$ - and (B) m-calpain in skeletal muscle of obese Zucker rats. The protein levels were determined by Western blot analysis. The $\alpha$-tubulin is internal control.

\section{Discussion}

The calpain system, a family of calcium-dependent cysteine protease, has been found for decades [23]. These calpain-isoforms might act independently through different proteosome pathway and cleave a number of cellular substrates, including kinases, phosphatases, transcription factors, and cytoskeletal proteins [24]. Calpain activity has been associated with cleavages that alter regulation of various enzyme activities, with remodeling or disassembly of the cell cytoskeleton, and with cleavages of hormone receptors [14]. Calpains involved in variety of physiological and pathological disorders [25]. Alterations in calpain-isoform activity might be related with a num- ber of disorders, including stroke [26,27], traumatic brain injury [26,27], Alzheimer's disease [26,27], cataracts [27], limb-girdle muscular dystrophy $[26,27]$ and gastric cancer [26].

At least 14 members of calpain-isoforms have been identified [26], including $\mu$-calpain, m-calpain, and calpain-10 [28]. Both $\mu$ - and m-calpain are heterodimers containing a $30 \mathrm{KD}$ small subunit and an 80 KD large subunit, which require micro-molar and milli-molar calcium concentrations for activation $[9,11$, 29]. The $\mu$-calpain is accompanied by limited autoproteolysis; $\mathrm{m}$-calpain could be activated by $\mu$-calpain [12]. Some genetic mutations of calpain-10 gene might be associated with an increased risk for NIDDM [7]. Altered expression of calpain 10 enzyme in pancreatic, muscle, and fat cells is related with abnormal glucose homeostasis through the modification of calpain 10-dependent pathway [7]. Low levels of calpain-10 mRNA in skeletal muscle were also associated with insulin resistance [13]. These findings suggested the related genetic and product expression of calpain-10 might play a major role in determining the normal response of skeletal muscle to the effects of insulin.

Several studies have confirmed the role of calpain 10 as a diabetes susceptibility gene $[7,18,19,27]$. Horikawa et al. firstly demonstrated the association between calpain 10 and DM [7]. They also highlighted the novel pathway of calpain system which contributed to the development of type 2 diabetes. The pharmacological inhibition of calpain might cause insulin resistance of glucose transport in skeletal muscle [30]. The m-calpain can degrade glucose transporter turnover, which provide evidence for a physiological role of calpains in the adjustment of muscle glucose equilibrium and muscle mass [31]. The calcium-dependent protease $\mu$-calpain is increased in the diabetic vasculature and that inhibition of calpain activity attenuates the vascular dysfunction associated with chronic diabetes, which indicated a role of calpain in the pathophysiology of diabetic vascular disease [32]. However, the mechanism regulating activity of the calpain system in-vivo is unknown.

At the cell membrane, calpain is activated in the presence of calcium and phospholipids. Calpain exists in the cytosol as an inactive enzyme and translocates to membranes in response to increases in the cellular $\mathrm{Ca}^{2+}$ level [29]. Calpains usually exhibit in an inactive form and are activated by calcium and phospholipids $[25,33]$. Calpain activity might be regulated by binding of $\mathrm{Ca}^{2+}$ to specific sites on the calpain molecule, with binding to each site eliciting a response (proteolytic activity, calpastatin binding, etc.) specific for that site. Calpains might bind to specific proteins and not to 
phospholipids, and that binding to cell membranes does not affect the $\mathrm{Ca}^{2+}$ required for autolysis [32]. The binding of the calpains to phospholipid in a cell membrane might lower the $\mathrm{Ca}^{2+}$ concentration, which is required for the autolysis of calpains. Furthermore, the autolysis of calpains converts an inactive proenzyme into an active protease [14].

Calcium-dependent protease calpain causes endothelial dysfunction and vascular inflammation in the microcirculation of the ZDF (Zucker diabetic fatty) rat, a genetic rat model of type 2 diabetes [32]. The inhibition of calpain activity in skeletal muscle is related to equilibrium in muscle metabolism [31]. Some investigators observed the increased calpain activity and leukocyte trafficking in the microcirculation of ZDF rats [32]. They also noted that inhibition of calpain activity significantly attenuated leukocyte-endothelium interactions in the vasculature of ZDF rats. Expression of cell adhesion molecules in the vascular endothelium of ZDF rats was consistently increased. Furthermore, the calpain inhibition might suppress the adhesion molecules between leukocyte and endothelium [32]. Therefore, calpains might become new molecular target for the prevention and treatment of diabetic vascular complications [32].

Calpain-10 is a non-lysosomal cysteine protease expressed in many tissues, including skeletal muscle, liver, and pancreas [13]. Calpain-10 is the first diabetes gene to be identified through a genome scan [34]. However, the function of calpain-10 remains unclear [35]. Calpain-10 gene is associated with NIDDM susceptibility [10]. Some calpain-10 single nucleotide gene polymorphism (SNP) is associated with reduced muscle mRNA levels and insulin resistance [13]. NIDDM-associated SNP-43*G-allele is associated with reduced calpain 10 mRNA levels, when compared to SNP-43*A-allele [36]. In contrast, some reports revealed their non-associations. Insulin had no significant effect upon calpain 10 mRNA levels [36]. In addition, age had no significant influence on calpain 10 mRNA levels [36].

In this survey, we observed the exercise decreased the expressions of both $\mu$ - and m-calpain mRNA, suggesting that the exercise might be related to the degradation of calpains in NIDDM rats. The calpain system changes after exercise might also influence and regulate the related pathways of glucose transport in skeletal muscle. Through the changes of body weight and the expressions of $\mu$-calpain and m-calpain mRNA in skeletal muscle, exercises improve the physiopathology of diabetic individuals. We found the benefits of exercise upon these lean rats, which indicated the favor roles of exercise upon the lean individuals with diabetes. Our findings also highlighted the possibilities of the roles of these calpains as possible markers for prognoses diabetes.

We also observed the lean Zucker rats with a $\mathrm{Fa} / \mathrm{Fa}$ or $\mathrm{Fa} / \mathrm{fa}$ genotype have decreased levels of calpain 10 mRNA. In contrast, there was no significant difference in calpain 10 expression between OE and OS groups. Furthermore, the calpain 10 expression of LS groups was lower than that pf LE groups. Our findings indicated that different biological mechanism and relationship between the calpain system and lower body weight condition. It also suggested that calpain 10 might not become useful marker for the diabetic screening.

Xiang et al. [37] found that the OS rats had significantly higher mean body weight, blood glucose, and insulin levels compared with the LS rats, whereas the OE had significantly lower blood glucose, and insulin levels compared with the OS. These results suggest that exercise training can improve body weight in the individuals with NIDDM [37]. Exercise training improves the insulin-stimulated glucose transport in muscle of the obese Zucker rats by increasing GLUT-4 content and by altering the normal intracellular distribution of these transporters such that they are capable of migrating to the cell surface in response to the insulin stimulus [38].

In this study, after 8 weeks exercise, we found the body weight difference between OS and OE rats was more significantly than that between LS and LE. These findings are in agreement with previous studies, which revealed that exercise training improves body weight controls of the obese rat. . The exercise training might be beneficial for lean rats too. We also observed the expressions of calpain $10, \mu$-calpain, and $\mathrm{m}$-calpain in obese rats were higher than those in lean rats. These findings suggested that both exercise and low body weight play similar influences upon the decreasing calpains expressions or increasing the calpains degradation, both were associated with glucose transport in the skeletal muscle of type 2 diabetes rats. The increased body weight might up-regulate the calpain mRNA levels, whereas the exercise might down-regulated the related expression.

In conclusion, exercise training decreases the body weight gaining in obese Zucker rats (type 2 diabetes). Exercise training appears to be an important determinant on the improvement of body weight control and expression of calpain-isoforms. The expressions of calpain isoforms in skeletal muscle are regulated by exercise training in both lean or obese Zucker rats, which suggest exercise can improve the glucose uptake into the contracting skeletal muscle in this model of NIDDM. The higher expressions of $\mu$ - or m-calpain mRNA might be risk factors for diabetic 
individuals. Both calpain-isoforms might become useful markers to predict the progression or prognosis of NIDDM. In contrast, the calpain 10 might not become useful candidate marker for the NIDDM screening. Although the real roles of calpain-isoforms have not been clarified, it deserves more attentions in the study of related correlations and the molecular mechanisms. Lager cohort recruitment is request for its further clarification. After the resolutions of these issues, some calpain-isforms might become useful markers to predict the future monitoring or screening of diabetes as well as the elucidation of related underlying pathways.

\section{Conflict of Interest}

The authors have declared that no conflict of interest exists.

\section{References}

1. Hayashi T, Wojtaszewski JF, Goodyear LJ. Exercise regulation of glucose transport in skeletal muscle. Am J Physiol. 1997;273(6 Pt 1):E1039-51.

2. Crettaz M., Prentki M., Zaninetti D., and Jeanrenaud B. Insulin resistance in soleus muscle from obese Zucker rats. Biochem J 1983;86: 525-534.

3. Brozinick JT Jr, Etgen GJ Jr, Yaspelkis BB 3rd, Kang HY, Ivy JL. Effects of exercise training on muscle GLUT-4 protein content and translocation in obese Zucker rats. Am J Physiol. 1993;265: E419-27.

4. Ayre KJ, Phinney SD, Tang AB, Stern JS. Exercise training reduces skeletal muscle membrane arachidonate in the obese (fa/fa) Zucker rat. J Appl Physiol. 1998;85: 1898-902.

5. Lee SD, Nakano H, Farkas GA. Adenosinergic modulation of ventilation in obese zucker rats. Obes Res. 2005;13: 545-55.

6. King PA, Horton ED, Hirshman MF, Horton ES. Insulin resistance in obese Zucker rat $(\mathrm{fa} / \mathrm{fa})$ skeletal muscle is associated with a failure of glucose transporter translocation. J Clin Invest. 1992;90: 1568-75.

7. Horikawa Y, Oda N, Cox NJ, Li X, Orho-Melander M, Hara M, et al. Genetic variation in the gene encoding calpain-10 is associated with type 2 diabetes mellitus. Nat Genet. 2000;26: 163-75.

8. Rasmussen SK, Urhammer SA, Berglund L, Jensen JN, Hansen L, Echwald SM, et al. Variants within the calpain-10 gene on chromosome 2q37 (NIDDM1) and relationships to type 2 diabetes, insulin resistance, and impaired acute insulin secretion among Scandinavian Caucasians. Diabetes. 2002;51: 3561-7.

9. Dayton WR, Reville WJ, Goll DE, Stromer MH. A Ca2+activated protease possibly involved in myofibrillar protein turnover. Partial characterization of the purified enzyme. Biochemistry. 1976;15: 2159-67.

10. Kang ES, Kim HJ, Nam M, Nam CM, Ahn CW, Cha BS, Lee HC. A novel 111/121 diplotype in the Calpain-10 gene is associated with type 2 diabetes. J Hum Genet. 2006; 51(7):629-33

11. Suzuki K, Imajoh S, Emori Y, Kawasaki H, Minami Y, Ohno S. Regulation of activity of calcium activated neutral protease. Adv Enzyme Regul. 1988;27: 153-69.

12. Sugita H, Ishiura S, Suzuki K, Imahori K. Ca-activated neutral protease and its inhibitors: in vitro effect on intact myofibrils. Muscle Nerve. 1980;3: 335-9.

13. Baier LJ, Permana PA, Yang X, Pratley RE, Hanson RL, Shen GQ. A calpain-10 gene polymorphism is associated with reduced muscle mRNA levels and insulin resistance. J Clin Invest. 2000;106: R69-73.
14. Goll DE, Thompson VF, Taylor RG, Zalewska T. Is calpain activity regulated by membranes and autolysis or by calcium and calpastatin? Bioessays. 1992;14: 549-56.

15. Yoshimura N, Murachi T, Heath R, Kay J, Jasani B, Newman GR. Immunogold electron-microscopic localisation of calpain I in skeletal muscle of rats. Cell Tissue Res. 1986;244: 265-70.

16. Hong DH, Huan J, Ou BR, Yeh JY, Saido TC, Cheeke PR, Forsberg NE. Protein kinase $C$ isoforms in muscle cells and their regulation by phorbol ester and calpain. Biochim Biophys Acta. 1995;1267: 45-54.

17. Ilian MA, Forsberg NE. Gene expression of calpains and their specific endogenous inhibitor, calpastatin, in skeletal muscle of fed and fasted rabbits. Biochem J. 1992;287 ( Pt 1):163-71.

18. Derbel S, Doumaguet C, Hubert D, Mosnier-Pudar H, Grabar S, Chelly J, Bienvenu T. Calpain 10 and development of diabetes mellitus in cystic fibrosis. J Cyst Fibros. 2006;5: 47-51.

19. Daimon M, Oizumi T, Saitoh T, Kameda W, Yamaguchi H, Ohnuma $H$, Igarashi $M$, Manaka $H$, Kato T. Calpain 10 gene polymorphisms are related, not to type 2 diabetes, but to increased serum cholesterol in Japanese. Diabetes Res Clin Pract. 2002;56: 147-52.

20. Herasse M, Ono Y, Fougerousse F, Kimura E, Stockholm D, Beley C, Montarras D, Pinset C, Sorimachi H, Suzuki K, Beckmann JS, Richard I. Expression and functional characteristics of calpain 3 isoforms generated through tissue-specific transcriptional and posttranscriptional events. Mol Cell Biol. 1999;19: 4047-55.

21. Bradford MM. A rapid and sensitive method for the quantitation of microgram quantities of protein utilizing the principle of protein-dye binding. Anal Biochem. 1976;72: 248-54.

22. Laemmli UK. Cleavage of structural proteins during the assembly of the head of bacteriophage T4. Nature. 1970;227: 680-5.

23. Guroff G. A neutral, calcium-activated proteinase from the soluble fraction of rat brain. J Biol Chem. 1964;239: 149-155

24. Sorimachi H, Ishiura S, Suzuki K. Structure and physiological function of calpains. Biochem J. 1997; 328 (Pt. 3):721-732

25. Suzuki K, Sorimachi H, Yoshizawa T, Kinbara K, Ishiura S. Calpain: novel family members, activation, and physiologic function. Biol Chem Hoppe Seyler. 1995;376: 523-9.

26. Huang Y, Wang KK. The calpain family and human disease. Trends Mol Med. 2001;7: 355-62.

27. Wang KK, Yuen PW. Calpain inhibition: an overview of its therapeutic potential. Trends Pharmacol Sci. 1994;15: 412-9.

28. Kent MP, Spencer MJ, Koohmaraie M. Postmortem proteolysis is reduced in transgenic mice overexpressing calpastatin. J Anim Sci Mar. 2004;82: 794-801.

29. Suzuki K, Ohno S. Calcium activated neutral protease--structure-function relationship and functional implications. Cell Struct Funct. 1990;15: 1-6.

30. Sreenan SK, Zhou YP, Otani K, Hansen PA, Currie KP, Pan CY, et al. Calpains play a role in insulin secretion and action. Diabetes. 2001;50: 2013-20.

31. Otani K, Han DH, Ford EL, Garcia-Roves PM, Ye H, Horikawa Y, Bell GI, Holloszy JO, Polonsky KS. Calpain system regulates muscle mass and glucose transporter GLUT4 turnover. J Biol Chem. 2004;279: 20915-20.

32. Stalker TJ, Gong Y, Scalia R. The calcium-dependent protease calpain causes endothelial dysfunction in type 2 diabetes. Diabetes. 2005;54: 1132-40.

33. Takai Y, Yamamoto M, Inoue M, Kishimoto A, Nishizuka Y. A proenzyme of cyclic nucleotide-independent protein kinase and its activation by calcium-dependent neutral protease from rat liver. Biochem Biophys Res Commun. 1977;77: 542-50.

34. Turner MD, Cassell PG, Hitman GA. Calpain-10: from genome search to function. Diabetes Metab Res Rev. 2005;21: 505-14.

35. Branca D. Calpain-related diseases. Biochem Biophys Res Commun. 2004;322: 1098-104. 
36. Carlsson E, Poulsen P, Storgaard H, Almgren P, Ling C, Jensen CB, Madsbad S, Groop L, Vaag A, Ridderstrale M. Genetic and nongenetic regulation of CAPN10 mRNA expression in skeletal muscle. Diabetes. 2005;54: 3015-20.

37. Xiang L, Naik J, Hester RL. Exercise-induced increase in skeletal muscle vasodilatory responses in obese Zucker rats. Am J Physiol Regul Integr Comp Physiol. 2005;288: R987-91.

38. Etgen GJ Jr, Jensen J, Wilson CM, Hunt DG, Cushman SW, Ivy JL. Exercise training reverses insulin resistance in muscle by enhanced recruitment of GLUT-4 to the cell surface. Am J Physiol. 1997;272: E864-9. 